\title{
TEORIA DE PATERSON E ZDERAD: APLICABILIDADE HUMANÍSTICA NO PARTO NORMAL*
}

Nayara Rubia Coelho', Lilian Maureira Vergara ${ }^{2}$

${ }^{1}$ Enfermeira. Universidade de Mogi das Cruzes. São Paulo, SP, Brasil.

${ }^{2}$ Enfermeira. Mestre em Enfermagem. Docente do Departamento de Enfermagem da Universidade de Mogi das Cruzes. São Paulo, SP, Brasil.

RESUMO: O processo de humanização no parto normal promove a "arte do cuidar humanizado" e a aplicabilidade da teoria humanística constitui um referencial teórico que permite subsídios na relação de troca existencial e dialógica entre enfermeiro e parturiente. O objetivo do estudo foi descrever e refletir a contribuição à relação teórico-prática humanizada no parto normal à luz da teoria humanística. Trata-se de um estudo de revisão bibliográfica, exploratório, descritivo de artigos on-line extraídos nas bases de dados: Latino-Americana e do Caribe em Ciências da Saúde, Base de Dados de Enfermagem e Scientific Electronic Library Online, publicados no período de 2002 a 2014. Os resultados evidenciaram que a teoria humanística fortalece a identidade do profissional, autonomia, necessidade de refletir o cuidado humanizado, resgatar a vivência do estar-com-ooutro, no encontro dialógico. Assim, o processo pautado na relação do encontro vivido e dialogado contribui para uma assistência eficaz e segura.

DESCRITORES: Enfermagem; Parto humanizado; Teoria de enfermagem.

\section{PATERSON E ZDERAD'S THEORY: HUMANISTIC APPLICABILITY IN NORMAL BIRTH}

\section{TEORÍA DE PATERSON Y ZDERAD: APLICABILIDAD HUMANÍSTICA EN EL PARTO NORMAL}

RESUMEN: El proceso de humanización en el parto normal promueve el "arte del cuidar humanizado", y la aplicabilidad de la teoría humanística constituye un referencial teórico que permite subsídios acerca del cambio existencial y dialógico entre enfermero y parturienta. El objetivo del estudio fue describir y reflexionar sobre la contribución a la relación teórica y práctica humanizada en el parto normal a la luz de la teoría humanística. Se trata de un estudio de revisión bibliográfica, exploratorio, descriptivo de artículos on-line obtenidos en las bases de datos: Latinoamericana y del Caribe en Ciencias de la Salud, Base de Datos de Enfermería y Scientific Electronic Library Online, publicados en el periodo de 2002 a 2014. Los resultados evidenciaron que la teoría humanística fortalece la identidad del profesional, autonomía, necesidad de reflexionar acerca del cuidado humanizado, recuperar la vivencia del estar-con-elotro, en el encuentro dialógico. Así, el proceso pautado en la relación del encuentro vivido y dialogado contribuye para una asistencia eficaz y segura.

DESCRIPTORES: Enfermería; Parto humanizado; Teoría de enfermería.

*Artigo extraído do trabalho de conclusão de curso intitulado: “Parto Normal e a Promoção da Humanização Frente à Teoria de Paterson e Zderad." Universidade de Mogi das Cruzes, 2014.

Autor Correspondente:

Nayara Rubia Coelho

Universidade de Mogi das Cruzes

Av. Raimundo Pereira de Magalhães, 8272 - 02938-000 - São Paulo, SP, Brasil

E-mail: nayararubia@ymail.com
Recebido: $16 / 03 / 2015$ Finalizado: 05/10/2015 


\section{INTRODUÇÃO}

Os enfermeiros vêm desenvolvendo e aplicando teorias na sua prática profissional com o intuito de melhoria da assistência à parturiente, com o advento das mudanças e novas tecnologias. $\mathrm{O}$ uso de modelo hegemônico medicalizado existente vem sendo questionado e discutido, por não conseguir diminuir consideravelmente os índices de morbimortalidade materna e perinatal, contribuindo para evidenciar a vulnerabilidade à vida e a qualidade na assistência, fatores que colocam em risco a saúde da parturiente.

Uma assistência com menos intervenção traduz o que é a humanização no centro obstétrico, além de levar mais motivação, respeito à dignidade, aos direitos sexuais e reprodutivos da mulher. A humanização pode ser descrita como o aumento da promoção de saúde, modificações da atenção e dos processos de trabalho, e tem como conceitos a troca e construção de saberes, trabalho em equipe e consideração aos interesses dos diferentes setores do campo da saúde ${ }^{(1)}$.

Deste modo, violências como negligência verbal, psicológica, física e sexual no campo obstétrico construíram, em longo do tempo, um cenário para a sociedade de crueldade e sofrimento no momento do parto e nascimento ${ }^{(2)}$. Segundo a pesquisa realizada, em 2010, pela Fundação Perseu Abramo: "Mulheres brasileiras e Gênero nos espaços público e privado", uma em cada quatro mulheres brasileiras sofre violência no parto $^{(3)}$.

Por outro lado, em prol da humanização, em 1996, a Organização Mundial de Saúde anunciou no documento assistência ao parto normal: um guia prático, no qual explicita as boas práticas de assistência ao parto normal ${ }^{(4)}$. No parto normal, a interferência no processo natural precisa seguir uma causa justa e com menos intervenção possível ${ }^{(5)}$.

Assim, no período gestacional até o puerpério de baixo risco, é permitido por lei o acompanhamento do enfermeiro obstétrico em nível de pós-graduação lato sensu. Essa conquista ocorreu, pois o profissional enfermeiro, além de prestar uma assistência à mulher com qualidade, também preconiza o cuidado humanizado ${ }^{(6)}$.

O uso e aplicabilidade da Teoria Humanística na assistência ao paciente constituem um referencial teórico à prática sistematizada, objetivando uma assistência efetiva e segura, contribuindo com alicerces evidenciados que permitam fortalecer e resgatar a verdadeira identidade da profissão na "arte de cuidar"(5).

O método da Teoria Humanísticaé denominado de Enfermagem Fenomenológica, fundamentada no existencialismo e na fenomenologia, composta por cinco fases ${ }^{(7)}$ estruturadas, segundo o método científico. Permitem ao enfermeiro aplicá-las tanto na assistência quanto na pesquisa. O profissional, na prática cotidiana, pode optar por utilizá-las como método para desenvolvimento de estudos, por meio do Processo de Enfermagem, para direcionar o fazer do cuidar da enfermagem ${ }^{(8-9)}$.

A Teoria de Enfermagem Humanística, criada por Josephine Paterson e Loretta Zderad, aplicada ao parto normal propõe desenvolver um diálogo verdadeiro e genuíno, para entender as necessidades da mulher. A Teoria Humanística propõe mudar o olhar a quem precisa de cuidado e que a enfermagem seja desenvolvida como uma experiência existencial ${ }^{(10)}$.

Deve-se ressaltar a importância do bem estar físico e emocional da parturiente, os quais favorecem a diminuição dos riscos e complicações para o bom andamento do trabalho de parto normal. Por isso, o respeito à privacidade, segurança e conforto, junto com o direito dos familiares durante a parturição, modificam o nascimento e o transformam em um momento exclusivo e específico ${ }^{(11)}$.

Diante desse panorama, o interesse em pesquisar a contribuição da humanização no parto normal à luz da teoria humanística passou a ter maior importância, e vem ganhando adeptos no contexto atual devido à intensificação e agravamento do fenômeno. Assim, o Programa Nacional de Humanização da Assistência Hospitalar (PNHAH), instituído pelo Ministério da Saúde mediante a portaria ${ }^{(12)} \mathrm{n}^{\circ} 881$, de 19 de junho de 2001, objetivou implementar ações para humanizar o atendimento da saúde e promover melhorias na qualidade dos serviços prestados aos pacientes. Entretanto, mesmo com a alta tecnologia existente podese observar a dificuldade em diminuir as taxas de morbimortalidade materna ${ }^{(1,13)}$, por causas evitáveis e relatos de maus tratos no processo de parto. Nesse sentido, faz-se necessário que o enfermeiro conheça e desenvolva práticas humanizadas ${ }^{(2)}$.

Considerando a relevância dessa temática, afirma-se a necessidade da realização de mais pesquisas acerca dessa prática, que possam mostrar a gravidade desse problema, contribuir 
com subsídios e melhorias à qualidade da assistência de enfermagem, abolir condutas que tornem vulneráveis, a vida e segurança da parturiente.

A prática e teoria de enfermagem não seriam completas sem uma metodologia. A Teoria Humanística ${ }^{(7)}$ contribui com estudos que refletem a importância e valorização da assistência de enfermagem à mulher, nos cenários acadêmico, assistencial e profissional, os quais geram contribuições para motivar uma mudança noato de assistir à mulher que procura por uma assistência segura $^{(2)}$, anular condutas que nascem no cerne da falta de adesão ao uso do guia de práticas e técnicas corretas humanizadas recomendadas por órgãos competentes ${ }^{(4)}$, e evidenciar a perda de identidade profissional pautada pelo uso inconsequente de técnicas do modelo biomédico e assistencialista ${ }^{(11)}$ que impedem o acolhimento humanizado e seguro. Deste modo, o estudo tem como objetivo descrever a contribuição da teoria humanística de Paterson e Zderad na prática humanizada do parto normal.

\section{MÉTODO}

Trata-se de um estudo de revisão bibliográfica descritivo, exploratório realizado via online utilizando-se como objetos artigos científicos indexados no acervo científico das bases de dados: Literatura Latino-Americana e do Caribe em Ciências da Saúde (LILACS), Base de Dados de Enfermagem (BDENF) e Scientific Electronic Library Online (SciELO). Para o levantamento dos artigos, utilizou-se como descritores: Enfermagem; Parto humanizado; Teoria de enfermagem. Os critérios de inclusão foram: artigos na íntegra disponíveis eletronicamente, que abordassem a temática, que ao menos um pesquisador fosse enfermeiro, pesquisas realizadas e divulgadas nos últimos 12 anos e ter pelo menos um descritor dentro dos escolhidos em Descritores em Ciências da Saúde (DeCS). O período de levantamento foi de 2002 a 2014. Foram excluídos os artigos que não atenderam aos critérios de inclusão mencionados. A coleta de dados foi executada nos meses de fevereiro de 2014 a outubro de 2015. Na intersecção dos descritores na base de dados após leitura exaustiva foram selecionados 37 artigos. Para organizar e analisar os achados, empregou-se a técnica de análise de conteúdo ${ }^{(14)}$. Os artigos foram lidos na íntegra e analisados com base no critério metodológico, usando as fases da pré-análise, exploração do material, tratamento e interpretação dos resultados ${ }^{(14)}$.

\section{RESULTADOS}

Nos artigos selecionados, houve prevalência de estudos nacionais. Para responder às questões de análise de descrever a contribuição da teoria humanística de Paterson e Zderad na prática humanizada do parto normal, foram levantados 146 artigos científicos, dos quais 30 (20,5\%) foram localizados na base de dados Literatura LatinoAmericana e do Caribe em Ciências da Saúde (LILACS), $47(32,2 \%)$ artigos na base de dados de Enfermagem (BDENF) e $69(47,3 \%)$ artigos na Scientific Electronic Library Online (SciELO).

Desse total, 109 artigos não atenderam aos critérios de inclusão, o que não significa que esses estudos não correspondiam ao tema, contudo não relatavam uma abordagem completa das fases. Realizou-se a leitura dos estudos na íntegra, buscando a interface entre a teoria humanística e o parto normal. Com a convergência dos achados, conseguiu-se identificar 11 subcategorias que estão inseridas nas cinco fases principais de análise das teoristas ${ }^{(6)}$ apresentadas no Quadro 1.

\section{DISCUSSÃO}

\section{$1^{\text {a }}$ Fase - Preparação do enfermeiro cognoscente para chegar ao conhecimento.}

Em relação aos enfoques da fase 1, os artigos deram ênfase ao: fortalecimento da identidade profissional; exercício das competências profissionais e projeção de apropriação de saberes, preparo e autonomia profissional, enfatizando ainda quais os principais fatores que interferem na preparação conhecedora do enfermeiro vir-a-conhecer para o surgimento do vínculo desse tipo de comunicação dialógica.

A partir da comunicação dialógica, surge o vínculo, em que se observa a disposição do enfermeiro que se envolve em aprender a correr riscos, estar aberto às experiências, ter uma própria visão do mundo e disponibilizar informações que irão favorecer a compreensão da parturiente em relação aos seus direitos, promovendo o respeito. Para atingir isto, o enfermeiro necessita ser exposto a uma ampla variedade de experiências, pode ser preparado em estudos e leituras das ciências humanas, onde são expressos vários pontos de vista sobre a natureza do $\operatorname{ser}^{(8,15-18)}$.

Assim, evidenciou-se a primeira fase, denominada: "Preparando-se para conhecer as parturientes". O enfermeiro obstetra prepara sua mente para o encontro com cada uma dessas mulheres, abrindo-se à experiência de encontrar 
Quadro 1 - Distribuição das subcategorias encontradas nos artigos, segundo os aspectos metodológicos e os processos de enfermagem. São Paulo, SP, Brasil, 2015

\begin{tabular}{|c|c|c|}
\hline TEORIA HUMANÍSTICA & $\begin{array}{l}\text { PROCESSO DE } \\
\text { ENFERMAGEM }\end{array}$ & SUBCATEGORIAS \\
\hline $\begin{array}{l}1^{\mathrm{a}} \text { fase - Preparação do } \\
\text { enfermeiro cognoscente para } \\
\text { chegar ao conhecimento; }\end{array}$ & & $\begin{array}{l}\text { Fortalecimento da identidade profissional }\left(\text { Caus }^{8}\right) ; \\
\text { Projeção de apropriação de saberes, preparo } \\
\text { e autonomia profissional }\left(\text { Oliveira }^{19} ; \text { Aguiar }^{20}\right) ; \\
\text { Fortalecimento do exercício das competências } \\
\left.\text { profissionais (Pereira }{ }^{22} ; \text { Figueiredo }^{23}\right) .\end{array}$ \\
\hline $\begin{array}{l}2^{a} \text { fase - O enfermeiro conhece } \\
\text { intuitivamente ao outro; }\end{array}$ & $\begin{array}{c}1^{\mathrm{a}} \text { etapa - } \\
\text { Coleta de dados de } \\
\text { enfermagem - dados } \\
\text { subjetivos (entrevista) }\end{array}$ & $\begin{array}{l}\text { Fortalecimento do resgate à vivência do estar- } \\
\text { com-o-outro, no cerne do eu-você no encontro } \\
\left(\text { Caus }^{8} \text {; Oliveira }{ }^{19} ; \text { Lélis }^{24} ; \text { Silva }^{26} ; \text { Campos }^{27} ;\right. \\
\left.\text { Farias }^{29}\right) .\end{array}$ \\
\hline $\begin{array}{l}3^{\text {a }} \text { fase - O enfermeiro conhece } \\
\text { cientificamente o outro; }\end{array}$ & $\begin{array}{l}1^{\mathrm{a}} \text { etapa - } \\
\text { Coleta de dados } \\
\text { - dados objetivos } \\
\text { (exame físico) }\end{array}$ & $\begin{array}{c}\text { Fortalecimento do resgate de olhar para o outro, } \\
\text { na sua essência, considerá-lo, analisá-lo como ser } \\
\left.\text { humano e até categorizá-lo (Caus }{ }^{8}\right) ; \\
\text { Afastar-se e refletir criticamente sobre a vivência } \\
\text { com o paciente ao mesmo tempo que está } \\
\text { inserida nela }\left(\text { Oliveira }{ }^{19}\right) \text {; Fortalecimento da } \\
\text { necessidade de refletir a relação sujeito-objeto no } \\
{\text { cuidado vivenciado }\left(\text { Caus }^{8} ; \text { Aguiar }\right.}^{20} \text {; Medeiros }{ }^{30} \text { ). }\end{array}$ \\
\hline $\begin{array}{l}4^{\text {a }} \text { fase }- \text { O enfermeiro sintetiza } \\
\text { complementariamente as } \\
\text { realidades conhecidas - } \\
\text { compara realidades múltiplas, } \\
\text { examina os dados e a } \\
\text { experiência do paciente à luz } \\
\text { do conhecimento científico e } \\
\text { sintetiza uma visão; } \\
\end{array}$ & $\begin{array}{c}2^{\mathrm{a}} \text { etapa - } \\
\text { Diagnóstico de } \\
\text { enfermagem } \\
3^{\mathrm{a}} \text { etapa - } \\
\text { Planejamento de } \\
\text { Enfermagem } \\
4^{\mathrm{a}} \text { etapa - } \\
\text { Implementação } \\
\end{array}$ & $\begin{array}{l}\text { Fortalecimento nas suas bases e aplicabilidade } \\
\text { dos conhecimentos possuídos para gerar uma } \\
\left.\text { relação dialógica (Ramos }{ }^{31} \text {; Silva }{ }^{34}\right) ; \\
\text { Capacidade de compreender a realidade do } \\
\text { fenômeno em estudo, a dor do outro, comparar } \\
\text { e sintetizar até o nexo dialógico, trabalhando as } \\
\text { diferentes realidades e diferenças }\left(\text { Caus }^{8}\right) \text {. }\end{array}$ \\
\hline $\begin{array}{l}5^{\mathrm{a}} \text { fase - Da sucessão das } \\
\text { multiplicidades à unidade } \\
\text { paradoxal com o processo } \\
\text { interno do enfermeiro - } \\
\text { compreensão do todo. }\end{array}$ & $\begin{array}{c}5^{a} \text { etapa- } \\
\text { Avaliação de } \\
\text { Enfermagem }\end{array}$ & $\begin{array}{l}\text { Reflexão do momento vivenciado (bem-estar) } \\
\text { e experimentado (vir-a ser). Fortalecimento à } \\
\text { preocupação de estar com alguém que está em } \\
\text { necessidade (Oliveira }{ }^{19} ; \text { Damansceno }{ }^{38} \text {; Morais }{ }^{39} \text { ). }\end{array}$ \\
\hline
\end{tabular}

o "outro" como um ser único e indivisível. O enfermeiro atuante fortalece a identidade profissional quando utiliza seu conhecimento adquirido e gera um vinculo de comunicação dialógica, tranquilidade e segurança para o outro (parturiente) perante o seu desenvolvimento normal $^{(7)}$.

O enfermeiro nesta fase trabalha o seu "EU", coloca em confronto seus valores morais e éticos para perceber sua capacidade de poder tornar suas atitudes mais humanas, estar receptivo para o desconhecido e disposto a ser surpreendido ${ }^{(18-20)}$.

Nessa perspectiva, após a portaria ${ }^{(21)} n^{\circ} 163 / 98$ que inseriu os enfermeiros obstetras na assistência direta (autonomia profissional) ao parto normal, identificou-se a diminuição no uso de episiotomia e intervenções desnecessárias, também foi possível identificar que os enfermeiros estão mais integrados à rotina assistencial na maternidade e compartilham desse momento de forma mais colaborativa com a equipe médica ${ }^{(22-23)}$.

Considera-se que a assistência humanística não se destaca apenas no cuidado existencial e integral, mas sim na prática embasada em conhecimentos técnicos e científicos para poder desenvolver um cuidado de qualidade, de modo que possa atender à cliente em sua individualidade ${ }^{(24-25)}$.

\section{$2^{a}$ Fase - $\mathrm{O}$ enfermeiro conhece intuitivamente ao outro.}

Nesta fase, os estudos mostram que é de ampla necessidade de conhecer o outro, a mistura do ser com o espírito rítmico do outro, gera-se o momento do encontro dialógico, da relação "EU - VOCÊ". Nesse contexto, levantamos a seguinte subcategoria para empregar como guia na fase dois: Fortalecimento do resgate à vivência do estar-com-o-outro, no cerne do "EU-VOCÊ" no encontro dialógico. 
Portanto, podemos relacionar nessa fase a primeira etapa do Processo de Enfermagem, no qual se encontra a Entrevista (Histórico de Enfermagem), e é de suma importância que no ato da coleta de dados exista o conhecimento intuitivo do enfermeiro, no ritmo da experiência da parturiente, o que resultava em um conhecimento especial difícil de expressar. O conhecimento intuitivo presume O relacionamento "EUVOCÊ", e também presume uma abordagem fenomenológica de estar aberto ao significado da experiência do outro, onde o enfermeiro deve ser capaz de captar intuitivamente, conhecer a visão da paciente ${ }^{(7-8,18,26-28)}$.

Desta forma, a teoria humanística de Paterson e Zderad, que defende a relação de troca entre enfermeiro e paciente, favorece a comparação e discutição de duas visões diferentes a respeito de um processo e auxilia na decisão do melhor a ser feito, uma relação de troca na qual a enfermagem, por meio do diálogo, estabelece um aprendizado existencial com a parturiente.

Por meio do objetivo de alcançar o bem estar e estar melhor, a parturiente encontra no enfermeiro um suporte e o enxerga como alguém disposto a ajudar. Esta relação é compreendida através de três características: a relação "EUVOCÊ" (sujeito-sujeito), a relação "EU-ISSO" (sujeito-objeto) e a relação "NÓS" (24, 29).

\section{$3^{a}$ Fase - $\mathrm{O}$ enfermeiro conhece cientificamente o outro.}

Esta fase implica uma separação do que é conhecido, afastar-se para estabelecer uma relação sujeito-objeto, e está relacionada à primeira etapa do processo de enfermagem ${ }^{(19)}$. Paterson e Zderad afirmam: "O desafio de comunicar uma realidade de enfermagem vivida demanda autenticidade do ser e um esforço rigoroso na seleção de palavras, de frases e da gramática precisa ${ }^{(7: 246) "}$. Assim, para direcionar o estudo nesta fase, iremos utilizar as seguintes subcategorias: Fortalecimento do resgate de olhar para o outro, na sua essência, considerálo, analisá-lo como ser humano até categorizá-lo; Afastar-se e refletir criticamente sobre a vivência com o paciente, ao mesmo tempo em que está inserida nela; Fortalecimento da necessidade de refletir a relação sujeito - objeto no cuidado vivenciado.

Desta forma, evidenciou-se a terceira fase, denominada: "Conhecendo cientificamente o outro: a relação EU-VOCÊ", a pesquisadora encarava os fenômenos já reconhecidos intuitivamente e meditava sobre eles, a fim de analisá-los, compará-los, interpretá-los, dar um nome a eles e categorizá-los ${ }^{(8)}$.

Por outro lado, existem outros estudos ${ }^{(8,20,30)}$ que permitem evidenciar a terceira fase. Nestes estudos, a fase é caracterizada pela relação "EU-ISSO" que ultrapassa os próprios limites, permitindo recordar, refletir e experimentar a relação "EU-VOCÊ" com "ISSO". Desta forma, esta fase implica em apresentar a interpretação das informações, conforme a proposta das teóricas pautadas na fenomenologia, em avaliar a parturiente com um exame físico completo e eficaz, finalizar a primeira etapa do processo de enfermagem de forma mais humanística e integrando a mulher para as demais etapas. Consiste na separação do que foi vivenciado e conhecido intuitivamente, interpretado, e recebe uma classificação conforme a relação entre as partes.

$4^{\text {a }}$ fase-Oenfermeirosintetizacomplementariamente as realidades conhecidas - compara realidades múltiplas, examina os dados e a experiência do paciente à luz do conhecimento científico e sintetiza uma visão.

$\mathrm{Na}$ quarta fase, encontra-se a busca pelo diagnóstico de enfermagem, planejamento e implementação do cuidado. Nessa fase ocorre o envolvimento da relação, comparação, e o contraste do que acontece nas situações para aumentar a compreensão de enfermagem da pessoa, compara e sintetiza as múltiplas realidades para, então, alcançar uma visão ampliada. Permite um diálogo entre as realidades e admite as diferenças. Assim, para guiar o nosso estudo nessa fase, iremos nos basear nas subcategorias citas a seguir: fortalecimento nas suas bases e aplicabilidade dos conhecimentos possuídos para gerar uma relação dialógica; capacidade de compreender a realidade do fenômeno em estudo, a dor do outro, comparar e sintetizar até o nexo dialógico, trabalhando as diferentes realidades e diferenças.

Nesse sentido, constata-se no estudo que a relação EU-TU ocorreu de acordo com o referido pelas teóricas, uma relação sujeitosujeito, em que o ser humano se envolve com o outro e tem consciência da singularidade ${ }^{(7)}$. Nesta fase o enfermeiro condensa e assemelha suas experiências vivenciadas, para chegar a um ponto de vista(19) e levantar seus diagnósticos. Após o profissional estabelecer ligações entre as realidades, ele seleciona e classifica suas prioridades $^{(19)}$, essa etapa definirá a qualidade do 
planejamento dos cuidados e sua implementação.

Ressalta-se ainda no estudo, que o enfermeiro necessita estar apto a apresentar os benefícios do parto normal para a gestante e evidenciar os riscos de uma cirurgia eletiva sem precisão. A Teoria Humanística de Paterson e Zderad defende transformar na prática tudo aquilo o que é humanamente possível na particularidade de cada situação. O dialogo é vivido de acordo com as ações de enfermagem, onde é necessária a compreensão do significado das experiências do outro, indo além de suas competências técnicas e científicas, conciliando a razão e a sensibilidade, para que assim possam juntos planejar um cuidado adequado com o propósito de defender o direito de escolha do cliente dentro do que é possível ${ }^{(31-34)}$.

A prática obstétrica atual tem valorizado a execução de um exercício profissional baseado em referenciais que priorizam a ampliação de habilidades técnicas, em detrimento de uma atenção que abranja as demandas emocionais das parturientes $^{(35)}$.

Deve-se atentar para a contraindicação de procedimentos habituais que ocorrem com frequência como jejum, tricotomia e enema de rotina. Porém, o apoio físico com a utilização de métodos não farmacológicos para a diminuição da dor deve ser promovido, por exemplo: banho de chuveiro, estimular a deambulação, mudança de decúbito, massagem, bola suíça, assento ativo, exercícios respiratórios, entre outros ${ }^{(36-37)}$.

Contudo, podemos entender por meio do estudo $^{(8)}$ que o diálogo nem sempre se estabelece por palavras ditas pela parturiente. Muitas vezes o gesto, o silêncio, expressão facial, suor, entre outros sinais, irão dizer mais sobre o que a cliente está sentido do que as palavras. Por isso, o enfermeiro deve desenvolver a percepção para esses sinais, para agir com eficácia e minimizar o sofrimento da parturiente, sempre estimulando sua confiança para seguir.

$5^{\mathrm{a}}$ fase - Da sucessão das multiplicidades à unidade paradoxal com o processo interno do enfermeiro compreensão do todo.

$\mathrm{Na}$ quinta fase, encontra-se a avaliação do processo de enfermagem, que por meio do diálogo com a parturiente, há o encontro e a presença do profissional com a cliente - a relação é recíproca entre ambas as partes. Desenvolve-se do processo descritivo de um fenômeno vivido, a visão articulada da experiência que se torna expressa em um todo coerente. Nesta etapa do estudo, iremos abordaras seguintes subcategorias: reflexão do momento vivenciado (bem-estar) e experimentado (vir-a-ser); fortalecimento à preocupação de estar com alguém que está em necessidade de acolhimento.

Nessa perspectiva, os estudos mostram que ocorre à conclusão de uma percepção importante para a maioria através de múltiplas visões e o enfermeiro estabelece sua opinião. Em cada uma dessas fases pode comparar e contrastar o fenômeno. A meta de bem-estar ou de vir-a-ser é atingida pelo diálogo. Na Teoria de enfermagem esse relacionamento é denominado "EU-VOCÊ" (relacionamento terapêutico) $)^{(19,38-39)}$.

Os estudos mostram que a teoria de Paterson e Zderad ganha familiaridade com a teoria de King. Destaca-se a possibilidade de criar uma interação entre o enfermeiro e o paciente com o objetivo de alcançar modelos pré - estabelecidos, denominados metaparadigmas e divididos em quatro lacunas: seres humanos, enfermagem, saúde e ambiente ${ }^{(40-41)}$. Em suma, verifica-se após a leitura, síntese das informações e reflexão dos achados, que cada fase dos resultados nos proporcionou um olhar de forma mais ampla ao processo de humanização frente à parturiente e o resgate da dignidade da mulher como protagonista do parto, com o apoio dialógico do enfermeiro que promove a troca existencial levando em consideração seu conhecimento teórico e técnico.

\section{CONSIDERAÇÕES FINAIS}

No processo de geração de vínculo com a parturiente, constatou-se que é essencial que o enfermeiro possua o preparo profissional para exercer atitudes, habilidades e competências, aliados a sentimentos, crenças e valores éticos e morais. Assim, a discussão da teoria humanística pelos profissionais de enfermagem está em efetivo desenvolvimento. Mostrou-se como um modelo que permite olhar para a parturiente com empatia e compreensão diante de sua dor, abertura para o diálogo vivido e encontro verdadeiro, busca ampliar seu nível de conhecimento humanizado, excelência e qualidade à assistência da parturiente.

A teoria humanística fortalece a identidade da profissão de enfermagem, gera autonomia ao profissional que outorga ao cuidado (encontro vivido e dialogado), permite a possibilidade de refletir a escolha do melhor cuidado com base em evidências científicas e resgatar a vivência do estarcom-o-outro (encontro dialógico). Evidenciouse que existe a citação nos estudos da aplicação 
das fases à assistência prestada, com adaptações e reconhecimento total delas, e mostraram-se estilos muito parecidos na condução das fases, preservando nexo vivenciado com o eixo do estudo teórico.

Portanto, o estudo não esgota o tema abordado. É essencial ao enfermeiro o papel como agente educador, gestor do diálogo vivenciado, que acolhe e interage com a parturiente, integra a família, prepara a equipe de enfermagem e atenta as novas estratégias de adesão de práticas humanizadas que resgatem a assistência digna, segura e eficaz, de respeito aos valores, sentimentos, crenças e cultura fortalecidos no elo de troca existencial e dialógica entre enfermeiro e parturiente.

\section{REFERÊNCIAS}

1. Progianti JM, Mouta RJO. A enfermeira obstétrica: agente estratégico na implantação de práticas do modelo humanizado em maternidade. Rev. Enferm. UERJ. 2009; 17(2):165-190.

2. D'Oliveira AFPL, Diniz SG, Schraiber LB. Violência contra a mulher em instituições de saúde: um problema emergente. The Lancet. 2002; 359(2):1681-5.

3. Silva MG, Marcelino MC, Rodrigues SLP, Toro RC, Shimo AKK. Violência obstétrica na visão de enfermeiras obstetras. Rev. Rene. 2014; 15(4):720-8.

4. Silva LR, Christoffel MM, Souza KV. História, conquistas e perspectivas no cuidado à mulher e à criança. Texto Contexto Enferm. 2005; 14(4):585-92.

5. Organização Mundial de Saúde (OMS). Assistência ao parto normal: um guia prático de saúde materna e neonatal. Maternidade segura. 1996. [acesso em 09 mar 2014]. Disponível: http://abenfo.redesindical.com. br/arqs/materia/56_a.pdf.

6. Dias MAB, Domingues RMSM. Desafios na implantação de uma política de humanização da assistência hospitalar ao parto. Ciênc. saúde colet. 2005; 10(3):669-705.

7. George JB. Teorias de enfermagem: os fundamentos à prática profissional.4 ${ }^{a}$ ed.Porto Alegre: Artes Médicas; 2000.

8. Caus ECM, Monticelli M, Nassif AA, Santos EKA. $O$ processo de parir assistido pela enfermeira obstétrica no contexto hospitalar: significados para as parturientes. Esc. Anna Nery. 2012; 16(1):34-40.

9. Cunhal PJ, Zagonel IPS. A relação dialógica permeando o cuidado de enfermagem em UTI pediátrica cardíaca. Rev. Eletr. Enf. 2006; 8(2):292-7.
10. Schaurich D, Crossetti MGO. Produção do conhecimento sobre teorias de enfermagem: análise de periódicos da área, 1998-2007. Esc. Anna Nery. 2010; 14(1):182-8.

11. Moura FMJSP, Crizostomo CD, Nery IS, Mendonça RCM, Araújo OD, Rocha SS. A humanização e a assistência de enfermagem ao parto normal. Rev. Bras. Enferm. 2007; 60(4):452-5.

12. Ministério da Saúde (BR). Gabinete do Ministro. Portaria $\mathrm{n}^{\circ}$ 881, de 19 de junho de 2001. Informes. [internet] 21 jun 2001 [acesso em 23/10/2015]. Disponível: $\quad$ sna.saude.gov.br/legisla/.../GM_ P881_01informes.doc.

13. Morse ML, Fonseca SC, Barbosa MD, Calil MB, Eyer FPC. Mortalidade materna no Brasil: o que mostra a produção científica nos últimos 30 anos?. Cad. Saúde Pública. 2011; 27(4):623-36.

14. Oliveira DC. Análise de conteúdo temáticocategorial: uma proposta de sistematização. Rev. Enferm. UERJ. 2008; 16(4):569-76.

15. Rattner D. Humanização na atenção a nascimentos e partos: breve referencial teórico. Interface (Botucatu). 2009; 13(1):595-602.

16. Ferreira-Júnior AR, Barros NF. A humanização do parto no cenário de disputas da obstetrícia. Physis. 2012; 22(4):1591-3.

17. Schneck CA, Riesco MLG, Bonadio IC, Diniz CSG, Oliveira SMJV. Resultados maternos e neonatais em centro de parto normal peri-hospitalar e hospital. Rev. Saúde Pública. 2012; 46(1):78-86.

18. Carvalho VF, Kerber NPC, Azambuja EP, Bueno FF, Silveira RS, Barros AM. Direitos das parturientes: conhecimento da adolescente e acompanhante. Saúde Soc. $2014 ;$ 23(2):572-581.

19. Oliveira NFS, Costa SFG, Nóbrega MML. Diálogo vivido entre enfermeira e mães de crianças com câncer. Rev. Eletr. Enf. 2006; 8(1):99-107.

20. Aguiar MIF, Braga VAB. O significado do transplante de fígado para o paciente em lista de espera: abordagem fenomenológica. Rev. Cubana Enfermer. 2012; 28(4):485-94.

21. Ministério da Saúde (BR). Secretária da Assistência à Saúde. Portaria $n^{\circ} 163$, de 22 de Setembro de 1998. Obstetrícia. [Internet] 24 set 1998 [acesso em 23/10/2015]. Disponível: http://abenfo.redesindical. com.br/arqs/outros/Portaria\%20163.pdf.

22. Pereira ALF, Araújo CS, Gouveia MSF, Potter VMB, Santana ALS. Resultados maternos e neonatais dos partos normais de baixo risco assistidos por enfermeiros e médicos. Rev. Eletr. Enf. 2012; 14(4):831- 
23. Figueiredo GS, Santos TTR, Reis CSC, Mouta RJO, Progianti MJ,Vargens OMC. Ocorrência de episiotomia em partos acompanhados por enfermeiros obstetras em ambiente hospitalar. Rev. Enferm. UERJ. 2011; 19(2):181-5.

24. Lélis ALPA, Farias LM, Cipriano MAB, Cardoso MVLML, Galvão MTG, Caetano JA. Cuidado Humanístico e percepções de enfermagem diante da dor do recém-nascido. Esc. Anna Nery. 2011; 15(4):694700 .

25. Dutra IL, Meyer DE. Parto natural, normal e humanizado: termos polissêmicos. Rev. Gaúcha Enferm. 2007; 28(2):215-222.

26. Silva LMP, Galvão MTG, Araújo TL, Cardoso MVLML. Cuidado à família de crianças em situação de abuso sexual baseado na teoria humanística. OBJN. [Internet] 2007; 6(1) [acesso em 02 ago 2014]. Disponível: http:// www.objnursing.uff.br//index.php/nursing/article/ view/715/162.

27. Campos ACS, Cardoso MVLML. O recém-nascido sob fototerapia: a percepção da mãe. Rev. Latino-Am. Enfermagem. 2004; 12(4):606-13.

28. Dodou HD, Rodrigues DP, Guerreiro EM, Guedes MVC, Lago PN, Mesquita NS. A contribuição do acompanhante para a humanização do parto e nascimento: percepções de puérperas. Esc. Anna Nery. 2014; 18(2):262-9.

29. Farias LM, Freire JG, Chaves EMC, Monteiro ARM. Enfermagem e o cuidado humanístico às mães diante do óbito neonatal. Rev. Rene. 2012; 13(2): 365-74.

30. Medeiros HMF, Motta MGC. Existir de crianças com AIDS em casa de apoio: compreensões à luz da enfermagem humanística. Rev. Gaúcha Enferm. 2008; 29(3):400-7.

31. Ramos AF, Caetano JÁ, Soares E, Rolim KMC. A convivência da família com o portador de síndrome de Down à luz da teoria humanística. Rev. Bras. Enferm. 2006; 59(3):262-8.

32. Winck DR, Bruggemann OM, Monticelli M. A responsabilidade do profissional na assistência ao parto: discurso de enfermeiras obstétricas. Esc. Anna Nery. 2012; 16(2):363-70.

33. Mercês CAMF, Rocha RM. Teoria de Paterson e Zderad: um cuidado de enfermagem ao cliente crítico sustentado no diálogo vivido. Rev. Enferm. UERJ. 2006; 14(3):470-75.

34. Silva LM, Barbieri M, Fustinoni SM. Vivenciando a experiência da parturição em um modelo assistencial humanizado. Rev. Bras. Enferm. 2011; 64(1):60-5.
Santana RCB, Fonseca MCC. Vivenciando o contato pele a pele com o recém-nascido no pós-parto como um ato mecânico. Rev. Bras. Enferm. 2014; 67(2): 202-7.

36. Muller J, Collaço VS, Santos EKA. O Significado para as puérperas do suporte profissional no processo parturitivo. Revista Cientifica CENSUPEG. 2013; (2):7888.

37. Tuesta AA, Giffin K, Gama AS, Orsi E, Barbosa GP. Saberes e práticas de enfermeiros e obstetras: cooperação e conflito na assistência ao parto. Cad. Saúde Pública. 2003; 19(5):1425-36.

38. Damansceno AKC, Pagliuca LMF, Barroso MGT. Aplicação dos conceitos da teoria humanística numa unidade de queimados. Rev. Rene. 2009; 10(2):78-85.

39. Morais GSN, Costa SFG. Experiência existencial de mães de crianças hospitalizadas em unidade de terapia intensiva pediátrica. Rev. Esc. Enferm. USP. 2009; 43(3):639-46.

40. Moura ERF, Pagliuca LMF. A teoria de King e sua interface com o programa "saúde da família". Rev. Esc. Enferm. USP. 2004; 38(3):270-9.

41. Rolim KMC, Pagliuca LMF, Cardoso LVLML. Análise da teoria humanística e a relação interpessoal do enfermeiro no cuidado ao recém-nascido. Rev. LatinoAm. Enfermagem. 2005; 13(3):432-40. 